\title{
Software development for energy auditing practice
}

\begin{abstract}
This paper presents the development of the software to calculate the energy usage. This software can be operated as an expert system. Basic architecture of the expert system contains knowledge base (database), inference engine (decision), graphical user interface (GUI), user and output (energy audit report). Mainly, this software was developed by using Microsoft Visual Basic as a programming language tool that can build the GUI. After testing it with previous and present collected energy data, this software can display the energy audit report. It presents total amount of energy usage in $\mathrm{kWh} / \mathrm{day}, \mathrm{kWh} / \mathrm{month}$ and total energy cost in RM.
\end{abstract}

Keyword: Software; Energy usage; Energy audit report 